\title{
Canadian Critical Care Society revised process for guideline development and endorsement
}

\author{
Francois Lamontagne, MD, MSc (D) - Frédérick D'Aragon, MD, MSc • \\ Karen E. A. Burns, MD, FRCPC, MSc • Émilie Belley-Côté, MD, MSc, FRCPC • \\ Michelle Kho, PT, PhD • Kusum Menon, MD, MSc • Erick Duan, MD • \\ Marie-Hélène Masse, RRT • Patrick Archambault, MD, MSc, FRCPC • \\ Carmen Hrymak, MD, FRCPC • Bram Rochwerg, MD, MSc
}

Received: 19 June 2018/ Accepted: 20 June 2018/Published online: 30 July 2018

(c) Canadian Anesthesiologists' Society 2018

\section{To the Editor,}

Clinical practice guidelines (CPGs) are "statements that include recommendations intended to optimize patient care that are informed by a systematic review of evidence and an assessment of the benefits and harms of alternative care options". ${ }^{1}$ Healthcare workers struggle to keep up with rapidly evolving scientific literature. In theory, CPGs constitute a comprehensive overview of the best available evidence addressing a specific clinical question and take into account considerations such as certainty in the evidence, patients' values and preferences, and resource

F. Lamontagne, MD, MSc ( $\varangle) \cdot$ F. D’Aragon, MD, MSc .

M.-H. Masse, RRT

Département de médecine, Faculté de médecine et des sciences de la santé, Université de Sherbrooke, 3001 12e avenue Nord,

Sherbrooke, QC J1H 5N4, Canada

e-mail: francois.lamontagne@usherbrooke.ca

F. Lamontagne, MD, MSc · F. D'Aragon, MD, MSc .

M.-H. Masse, RRT

Centre de recherche du CHU de Sherbrooke, Sherbrooke, QC, Canada

K. E. A. Burns, MD, FRCPC, MSc

Interdepartmental Division of Critical Care Medicine, University

of Toronto, Toronto, ON, Canada

K. E. A. Burns, MD, FRCPC, MSc

Li Ka Shing Knowledge Institute, St Michael's Hospital,

Toronto, ON, Canada

K. E. A. Burns, MD, FRCPC, MSc · E. Duan, MD .

B. Rochwerg, MD, MSc

Health Research Methods, Evaluation and Impact, McMaster

University, Hamilton, ON, Canada

É. Belley-Côté, MD, MSc, FRCPC · M. Kho, PT, PhD

McMaster University, Hamilton, ON, Canada use or cost. These factors are used to generate actionable and trustworthy recommendations, which may inform clinician-patient discussions and shared decision-making. ${ }^{2}$ Reducing the gap between scientific evidence and actual practice may improve the safety and efficiency of healthcare interventions. ${ }^{3}$ In contrast, failure to adhere to these high standards when developing guidelines may lead to erroneous conclusions.

In 2011, the Institute of Medicine published standards for the development of "Trustworthy Guidelines", classified by the following domains: 1) the clinical

K. Menon, MD, MSc

University of Ottawa, Ottawa, ON, Canada

K. Menon, MD, MSc

Children's Hospital of Eastern Ontario, Ottawa, ON, Canada

P. Archambault, MD, MSc, FRCPC

Population Health and Optimal Health Practices Research Unit, Trauma-Emergency-Critical Care Medicine, Centre de recherche du CHU de Québec-Université Laval, Quebec, QC, Canada

P. Archambault, MD, MSc, FRCPC

Division of Critical Care Medicine, Department of

Anesthesiology and Critical Care Medicine, Faculty of

Medicine, Université Laval, Quebec, QC, Canada

P. Archambault, MD, MSc, FRCPC

Department of Family and Emergency Medicine, Faculty of Medicine, Université Laval, Quebec, QC, Canada

C. Hrymak, MD, FRCPC

Department of Internal Medicine, Section of Critical Care, Rady

Faculty of Health Sciences, Max Rady College of Medicine,

University of Manitoba, Winnipeg, MB, Canada 
question addressed by the recommendation should be explicit - i.e., without a clear question, it is impossible to obtain the crucial knowledge needed to inform the CPGs; 2) all relevant stakeholders (i.e., patients, caregivers, members of the public) should have the opportunity to contribute to the discussions - guideline panels lacking diversity may develop tunnel vision and fail to take other important perspectives into consideration; 3 ) rigorous and up-to-date systematic review(s) and data syntheses must inform the panel discussions and the link between recommendations and the underlying evidence made clear; 4) the process of making recommendations should be explicit - i.e., frameworks such as Grading of Recommendations Assessment, Development, and Evaluation (GRADE) ${ }^{4}$ provide structure and transparency in distinguishing the quality of underlying evidence from the strength of the recommendation; 5) the recommendations should be clear, actionable, and unambiguous; 6) guideline panels should consider all potential risks and benefits associated with the clinical question, the impact of different patient values and preferences, as well as resources and acceptability implications; 7) financial conflicts of interest should be avoided entirely, and intellectual conflicts of interest that cannot be avoided should be minimized and reported transparently.

Managing conflicts of interest - real or perceived - may be the most crucial and challenging. Professional societies are commonly asked to endorse guidelines created by their own members, ${ }^{5,6}$ which in itself may be perceived as a conflict of interest as an organization is unlikely to reject its own work. Moreover, there are often secondary gains for professional organizations that, on one hand receive financial support from industry, and on the other disseminate recommendations that may influence profitability of said industry.

The Canadian Critical Care Society (CCCS) previously lacked a formal review process and clear criteria for endorsing CPGs. In 2016, the CCCS Knowledge Translation Committee reviewed its CPG endorsement policy to formalize the endorsement process. Accordingly, CCCS members with content and methodology expertise were invited to join this committee as a group of qualified guideline reviewers. The AGREE-II Instrument was adopted to appraise submitted CPGs and ensure they were produced using proper methods. ${ }^{7,8}$ This made the criteria that guide the CCCS' endorsement of CPGs explicit. We also addressed the perception that involvement of CCCS members in CPG creation was the only requirement to be endorsed by the Society. Although we still encourage inclusion of CCCS members in the CPG development process, the CCCS now pledges to critically appraise all CPGs that are submitted for endorsement using explicit criteria (i.e., AGREE-II) in a manner that reduces the potential for bias. When unbiased internal review is not possible, we will entrust the appraisal process to partner organizations who share our vision of trustworthy guidelines.

The CCCS acknowledges that the science of knowledge translation extends well beyond CPGs and we are committed to improving how we support an efficient national critical care system. Meanwhile, the recently implemented process defines the criteria that determine whether CPGs are trustworthy and therefore worthy of endorsement. As such, it constitutes the cornerstone for future activities of the Knowledge Translation Committee.

Conflicts of interest None declared.

Editorial responsibility This submission was handled by Dr. Hilary P. Grocott, Editor-in-Chief, Canadian Journal of Anesthesia.

\section{References}

1. Institute of Medicine (US); Committee on Standards for Developing Trustworthy Clinical Practice Guidelines. Graham R, Mancher M, Miller Wolman D, Greenfield S, Steinberg E (Eds). Clinical Practice Guidelines We Can Trust. Washington, DC: National Academies Press; 2011.

2. Légaré F, Stacey D, Forest PG, et al. Milestones, barriers and beacons: shared decision making in Canada inches ahead. Z Evid Fortbild Qual Gesundhwes 2017; 123-124: 23-7.

3. Woolf SH, Grol R, Hutchinson A, Eccles M, Grimshaw J. Clinical guidelines: potential benefits, limitations, and harms of clinical guidelines. BMJ 1999; 318: 527-30.

4. Guyatt $G$, Oxman AD, Akl EA, et al. GRADE guidelines: 1. Introduction-GRADE evidence profiles and summary of findings tables. J Clin Epidemiol 2011; 64: 383-94.

5. Rochwerg B, Hylands M, Moller M, et al. CCCS-SSAI WikiRecs Clinical Practice Guideline: vasopressor blood pressure targets in critically ill adults with hypotension. Can J Anesth 2017; 64: 7635 .

6. Rochwerg B, Hylands $M$, Moller $M$, et al. CCCS-SSAI WikiRecs Clinical Practice Guideline: vasopressors in early traumatic shock. Can J Anesth 2017; 64: 766-8.

7. Brouwers MC, Kho ME, Browman GP, et al. Development of the AGREE II, part 1: performance, usefulness and areas for improvement. CMAJ 2010; 182: 1045-52.

8. Brouwers MC, Kho ME, Browman GP, et al. Development of the AGREE II, part 2: assessment of validity of items and tools to support application. CMAJ 2010; 182: E472-8. 